\title{
O ELO ENTRE A PRODUÇÃO, O CONSUMO E A COMUNICAÇÃO MERCADOLÓGICA DA CACHAÇA ARTESANAL ORGÂNICA MINEIRA ${ }^{1}$
}

\author{
THE LINK BETWEEN PRODUCTION, CONSUMPTION AND MARKETING \\ COMMUNICATION OF ORGANIC ARTISAN CACHAÇA MINEIRA
}

\author{
Víviam Lacerda de Souza*
}

\begin{abstract}
RESUMO
Esse trabalho trata da importância de se compreender o mercado de produção e consumo da cachaça artesanal orgânica no estado de Minas Gerais, tendo em vista questões como a origem, a cultura local, a qualidade, a sociabilidade e a moralidade, fenômenos que se inserem no universo do produto e são apropriados no âmbito da comunicação mercadológica. Por meio de análise bibliográfica, fundamentamonos em estudos sobre o mercado de cachaça e das implicações a respeito da comunicação mercadológica, gastronomização e propriedade intelectual, moral e consumo, além das questões das políticas públicas que envolvem o produtor familiar, o mercado orgânico e, por fim, o folkmarketing.
\end{abstract}

Palavras-chave: Mercado. Consumo. Produção. Cachaça. Comunicação.

\begin{abstract}
This paper discusses the importance of understanding the production and consumption market of organic cachaça in the state of Minas Gerais, considering issues such as origin, local culture, quality, sociability and morality; phenomena which are part of the universe of the product and are appropriate in the context of marketing communications. Through a literature review, this paper is based on studies of the cachaça market; studies about gastronomization and intellectual property; moral and consumption; family producer; public policies; marketing communication; organic market and finally folkmarketing.
\end{abstract}

Keywords: Market. Consumption. Production. Cachaça. Communication.

\footnotetext{
${ }^{1}$ Artigo apresentado na II Conferência Brasileira de Estudos em Comunicação e Mercado, na Universidade Makenzie, em São Paulo, Agosto de 2012.

* Doutoranda em Comunicação pela Universidade Metodista de São Paulo (UMESP), mestre em Administração, Educação e Comunicação pela Universidade São Marcos e graduada em Comunicação Social - Publicidade e Propaganda pelo Centro Universitário Ibero-Americano (UNIBERO).
} 


\section{Cachaça: do consumo à postura social}

Caninha, água que gato não bebe, pinga, branquinha, perigosa são algumas formas populares de referência à bebida cachaça, que é originária do mosto, também conhecido por borra ou cachaza. Diante da importância histórica, social, cultural e mercadológica deste produto, foram criados os Decretos 2.314/97 e 4.851/03 do Artigo 92, que protegem a propriedade da nominação "cachaça" sob a Lei no 8.918 de 14 de julho de 1994 (SEBRAE, 2008, p 15), confirmando a designação exclusiva para a aguardente de cana, produzida no Brasil. Com graduação alcoólica de trinta e oito a quarenta e oito por cento em volume, através do processo de destilação a vinte graus Celsius, se origina a bebida do mosto fermentado de cana-de-açúcar, com possibilidade de adição de açúcar de até seis gramas por litro, sob forma de sacarose.

A cachaça, além de fazer parte do cenário histórico e cultural do Brasil, mostra-se no contexto contemporâneo inserida não só no mercado nacional como também no mercado internacional. Neste sentido, cabe nesta proposta de pesquisa, por meio de análise bibliográfica, reconhecer, compreender os significados e representações do universo consumidor da cachaça artesanal orgânica, frente às questões sociais e morais de consumo do produto. Nota-se que as necessidades e desejos deste público consumidor influem diretamente na demanda mercadológica de forma a estimular mudanças no processo de produção, as quais são capazes de transformar a rotina de trabalho do produtor.

No que diz respeito à questão cultural, a cachaça apresenta-se em um processo de mudança de status, que podemos chamar de gastronomização do produto, que tem contribuído significativamente para um consumo nacional diferenciado, pois o seleto público mostra-se exigente e com maior poder aquisitivo.

Gastronomização, por sua vez, se refere à estetização, ritualização, valorização do sabor e do prazer conferido à cachaça. Essa tendência possui como característica a passagem do consumo cotidiano e automático para um ação prazerosa, de lazer, sociabilidade e comensalidade, observado como uma questão de gosto, cultura e tradição (BARBOSA, 2009.
Ao se analisar a questão do consumo da cachaça diante da liberdade de escolha, reconhecemos que a própria palavra consumo é muitas vezes depreciada diante do que é considerado como aceito ou não aceito socialmente, o que reflete uma ação cultural.

Neste contexto, torna-se necessária a elucidação da estreita relação entre consumo e moralidade, que nos conduz à crença de que o próprio discurso do consumo implica aspectos morais, pois no momento decisivo da escolha há confrontos e justificativas, o que evidencia os perigos do moralismo e também sua necessidade.

Para Gonçalves (2006, p. 82), a condenação moral salienta particulares tipos de consumo, entre os quais alguns são bons e outros não. A distinção entre ambos é fundamentada na posição econômico-social dos consumidores, ou seja, uma aquisição específica acarreta críticas morais que destacam a desigualdade social dos que se limitam economicamente.

O consumo, apesar de ser uma atividade livre, possui inúmeras restrições, logo, há uma contradição no enfoque moralista diante do caráter construtivo ou destrutivo, do veículo de dominação ou resistência, ou até de ambos, que se resume na tensão evidente em cada escolha de consumo.

Neste contexto, os indivíduos muitas vezes se deparam com o autopoliciamento para alcançarem níveis de satisfação e prazer sem exceder ou prejudicar a si mesmos ou às necessidades das gerações futuras. Surge um problema moral fundamental: a definição de limites autônomos e da capacidade pessoal de efetuar boas escolhas, observadas como certas ou 'conscientes' no que diz respeito a consumo. Afiguram-se, então, dois tipos básicos de consumo, o não condenável e o condenável (GONÇALVES, 2006).

Sendo assim, o estilo de vida contemporâneo denota a individualidade, a autoexpressão e a consciência de si próprio, ou seja, o ato de decidir o que fazer, como agir e quem ser exige respostas individuais que envolvem a reflexão em um contexto cultural, o que permite a trajetória lógica da vida. Portanto, ser independente envolve assumir riscos em um universo diversificado e repleto de possibilidades.

Deste modo, a autorrealização ocorre em razão do equilíbrio entre oportunidade e risco, pois a sociedade proporciona diversas e distintas formas de agir e pensar. A busca pela realização pessoal demanda uma lógica genuína de fé e confiança, ou seja, de au- 
tenticidade, de ser verdadeiro e realista consigo mesmo, uma questão de moral, de estimular o sentido do 'bom', da dignidade. Surge, então, o desejo de completude e integridade dentro de um sistema de crenças e valores, por meio do qual o indivíduo seja reconhecido e construa a sua história de vida.

Entretanto, vale ressaltar que a moralidade, absorvida pelas práticas e pelo contexto cultural, acaba por moldar circunstâncias, atitudes, discursos e ações de consumo. É o caso específico do consumo da cachaça, cuja regulação surge como consequência da moralidade, da condenação e da necessidade de um conjunto de normas e regras capazes de estabelecer limites e condutas, como se pode observar nos projetos governamentais legitimados para validar a lei de controle para bebidas alcoólicas e outros produtos de consumo privado.

No momento em que surgem práticas sociais conflituosas que prejudicam outras atividades, há a necessidade de uma regulação por parte das classes dominantes ou da ação delas nas camadas sociais em desenvolvimento. Por isso, desde as chamadas leis suntuárias, criadas na passagem da era medieval para o início da Europa moderna, com o intuito de regular o consumo exagerado de determinados bens, têm sido delimitadas regras que se preocupam com manifestações de consumo considerado como conspícuo e que buscam o bem-estar social coletivo.

Para Gonçalves (2006), o sentido moral e a análise histórica das leis suntuárias permitem atestar que elas regram o consumo em geral, tanto no sentido social quanto no moral, sendo, portanto, uma mudança de conotação na lei atual. Em suma, a ética suntuária permanece vigorosa nos projetos de regulação moral, embora isenta de características econômicas e hierárquicas que tinham sido dominantes em seus primórdios.

Assim, o consumo individual não se caracteriza como uma escolha privada, isolada da esfera legal, pois, ao contrário, sobrevive no foco da atual intervenção regulatória, cuja característica básica reside em indicar o imoral e o danoso, tanto para a saúde do indivíduo quanto para o bem-estar social, o que mostra os resquícios dos projetos suntuários.

Dentro desse contexto, as restrições ao consumo apresentam-se pertinentes nos projetos sustentados por duas razões: a alta moralidade sobre o consumo, como a criminalização das drogas, ou a condenação por gastos excessivos; e os alarmes médicos e intervenções profundas na sociedade, como as questões do álcool.

\section{Mercado da cachaça industrial e da cachaça artesanal}

Deste modo, torna-se necessário compreender o contexto mercadológico da cachaça para adiante analisarmos seu público consumidor. Sendo assim, partimos dos aspectos de produção e diferenciação da bebida.

A cachaça industrial é produzida em destiladores de coluna, também conhecidos como destiladores contínuos para a fermentação com adição de produtos quimicamente sintetizados, e a matéria-prima, a cana-de-açúcar, é produzida em culturas de grande escala, com utilização de agroquímicos, colheita mecanizada e uso esporádico de queima da palhada; já a cachaça artesanal é produzida em alambiques, com fermentação natural, matéria-prima própria, cuja colheita é manual e sem o uso de queimadas (SEBRAE, 2008).

Segundo a Associação Brasileira de Bebidas - ABRABE (2011), o mercado de bebidas nacional, em relação ao volume consumido é dividido entre cerveja, num total de $88,8 \%$, seguido de cachaça, com $6,6 \%$, e demais bebidas em $4,6 \%$.

Ao considerarmos exclusivamente o mercado de bebidas destiladas, o volume de consumo mostra-se ainda mais considerável, visto que a cachaça ocupa a primeira posição no país, pois detém uma fatia mercadológica de 87\% (SEBRAE, 2008, p 19), o que resulta em um crescimento favorável em termos monetários e em uma produção nacional de aproximadamente 1,4 bilhão de litros da bebida ao ano, divididos em $70 \%$ para cachaça industrial e 30\% para cachaça artesanal.

Estima-se que o mercado da cachaça no Brasil seja composto por cerca de 30 mil produtores responsáveis por mais de cinco mil marcas existentes. Tais produtores geram mais de 400.000 empregos diretos e um faturamento anual de mais de U\$600 milhões (SEBRAE, 2008).

Ao se observar o mercado de cachaça, partimos da premissa de que o volume produzido em litros representa um crescimento, fruto de incentivo criado por diversos programas de promoção da bebida, 
além da própria questão cultural, no que se refere à mudança de status do produto, que passa a ser consumido nacionalmente por um seleto público, exigente e com maior poder aquisitivo. Outro fator que contribui para tal crescimento são as exportações.

De acordo com estimativas citadas por VERDI (2006, p.93-98), o volume de exportação da cachaça artesanal é pouco significativo, pois ainda corresponde a um total abaixo de $2 \%$ da produção. Essa exportação é destinada principalmente à Alemanha, seguida de Paraguai, Portugal, Uruguai e Estados Unidos JAKUBASZKO (et al., 2005).

Aparentemente, o consumo da cachaça artesanal, totalizado em 419,7 milhões de litros, é basicamente do mercado interno (SEBRAE, 2008). Esse consumo anual provavelmente é bem maior, porém não mensurado em decorrência da informalidade e do consumo não declarado.

Deste modo, o estado de Minas Gerais, em termos geográficos, apresenta-se como o principal produtor de cachaça de alambique do país, cuja participação corresponde a $15 \%$ do mercado total da bebida (artesanal e industrial) e, em termos de cachaça artesanal, o estado detém $50 \%$ do mercado nacional. São 8.500 alambiques de cachaça e 600 marcas registradas no Ministério da Agricultura. Desse total, $43 \%$ da produção pertencem a estabelecimentos registrados, e $57 \%$ a clandestinos, sendo que $45 \%$ dos estabelecimentos são de pequeno porte, e os outros $55 \%$, de médio e grande porte (SEBRAE, 2008). Vale lembrar que o porte dos produtores e seus respectivos estabelecimentos é classificado de acordo com sua capacidade de produção de litros de cachaça. Assim, os produtores artesanais caracterizados como de pequeno porte produzem até 10.000 litros/ safra e uma produção aproximada de 23 litros/dia, já os produtores profissionais de médio porte produzem cerca de 10 mil a 40 mil litros/safra e 104 litros de cachaça/dia e, por fim, os produtores empresariais de grande porte produzem a bebida acima de 40 mil litros/safra e 709 litros/dia.

Em se tratando dos pequenos produtores ou produtores artesanais, eles são representados por empresas familiares que geralmente têm na produção de cachaça uma complementação da renda, principalmente na entressafra agrícola. Esse fato ocorre em mais de 50\% dos casos, em que há a associação de outras atividades agrícolas como feijão, milho, café e leite, produtos típicos da região de Minas Gerais (SEBRAE, 2008, p 45).

Compreendemos essas empresas de pequenos produtores como unidades familiares de produção, sustentadas pela íntima relação entre trabalho e parentesco, que apresentam uma maior margem de negociação interna no planejamento de vias alternativas de reprodução social (CARNEIRO, 2008).

Nesse contexto, torna-se claro as práticas de pluriatividade que designam reconhecer atividades não agrícolas como constitutivas da dinâmica social da agricultura familiar. Percebemos claramente a coexistência de processos sociais distintos, até contraditórios, determinados pelas possibilidades de realização dos projetos familiares. Em relação a essas possibilidades, entende-se que o universo para planejamento e concretização de projetos é definido pela associação entre condições sócio-econômicas e fatores pertinentes às unidades familiares, tais como o capital cultural e material, a fase de desenvolvimento do grupo doméstico, composição etária e sexual dos membros familiares, assim como a posição dos indivíduos que exercem a atividade não agrícola na hierarquia familiar (CARNEIRO, 1999).

Pensar em agricultura familiar pluriativa é considerar a família como uma unidade social e não apenas como unidade de produção. Desta forma, a pluriatividade apresenta-se resultante de reflexões políticas sobre a atuação pública no meio rural e contribui para a recuperação da agricultura como modo de vida, incorporada ao conjunto da sociedade e fundamentada em um território, onde ocorre a disputa pela legitimidade entre novas identidades sociais atuantes no contexto rural contemporâneo.

Constata-se que essa população rural, mesmo inserida no mercado de trabalho e marcada pelas frequentes trocas de bens materiais e simbólicos, não se designa à homogeinização, o que enfatiza a ruralidade como um processo dinâmico em constante reestruturação dos elementos de cultura local, a partir do agrupamento de novos valores, hábitos e técnicas (CARNEIRO, 2002). Tais características são identificadas em diversas regiões do país, onde o produtor artesanal sofre a falta de recursos necessários para investir na produção da cachaça, e na própria cultura de cana-de-açúcar, o que promove o desafio das políticas públicas em busca de sistemas de base ecológica e programas de desenvolvimento da agropecuá- 
ria orgânica. Além disso, esse produtor apresenta-se carente de informações indispensáveis à legalização de sua atividade, melhoria da qualidade do produto e mesmo da produtividade, o que pode contribuir significativamente para a inserção em mercados mais lucrativos, como o externo.

Neste aspecto, Wilkinson (2008) afirma que para esses casos existem orientações em torno de clusters ou união de empresas, que visam à competitividade em mercados nacionais e internacionais, por meio de um conjunto de vantagens de proximidade, situação em que a pequena produção pode girar em torno de atores maiores. São estratégias de qualidade superior que destacam valores das tradições e do artesanal, focados na pequena produção.

Em relação à agregação de valor, pode se considerar a questão da Indicação Geográfica, caso em que o Instituto Nacional de Propriedade Industrial INPI (2011) conceitua a identificação de um produto em função de sua procedência - local, região ou país -, quando determinada reputação, característica e/ou qualidade possam ser vinculadas a esta sua origem particular. Ou seja, trata-se de uma garantia quanto à origem de um produto e/ou suas qualidades e características regionais.

Dessa forma, o INPI protege o produto sob a espécie de Indicação de Procedência, que se caracteriza pela autenticidade do nome geográfico conhecido pela produção, extração ou fabricação de determinado produto, ou pela prestação de determinado serviço, capaz de viabilizar a agregação de valor sempre que indicada a sua origem, independentemente de outras características.

Outra espécie protegida é a da Dominação de Origem que zela pelo nome geográfico que indique produto cujas qualidades ou características remetam exclusiva ou essencialmente à área geográfica, o que compreende os fatores naturais, como clima, temperatura, altitude, umidade e composição do solo, entre outros; também os fatores humanos, que são os saberes e as práticas culturais tradicionalmente repassadas ao longo das gerações (BARBOSA, 2011).

Tais proteções facultadas pela Indicação Geográfica possuem natureza declaratória, uma vez que implicam o reconhecimento estatal das condições pré-existentes de reputação ou influência do meio geográfico em questão, o que se insere no contexto do Direito Privado, sob a lei expressa no parágrafo único do Art. $1^{\circ}$ da Resolução INPI n ${ }^{\circ} 075$.

Barbosa (2011, p. 39-40) afirma que "a utilização de ativos protegidos pelo Sistema de Propriedade Intelectual para proteção de produções de populações tradicionais ainda é bastante recente e controverso". $\mathrm{O}$ fato se explica com as incompatibilidades conceituais e dificuldades práticas da utilização da Proteção Intelectual (P.I.) capazes de proteger conhecimentos tradicionais, pois a maioria dos seus instrumentos de proteção não se destina à proteção de conhecimentos tradicionais coletivos, uma vez que se aplicam a direitos individuais porque requerem titularidade. Além disto, há a questão da privatização do conhecimento, inerente ao conceito de propriedade, que se confronta com o sistema de valores da maioria das comunidades tradicionais.

Barbosa (2011) acredita na sugestão de teóricos a respeito da adequação das ferramentas de P.I. à realidade, pois se trata de um conjunto de direitos que poderiam ser utilizados a favor das populações produtoras ao acessarem ou serem acessados pela economia de mercado de qualidade.

Em decorrência de a construção de mercados de qualidade geralmente não se iniciar por meio de debates entre os produtores, mas sim pelos agentes externos, a maioria desses produtores desenvolvem expectativas em relação aos benefícios, sem calcular previamente os custos, que são: capacitação para o controle de qualidade da produção e exigências burocráticas, para a relação com o dinheiro em termos de divisão das despesas, rendas, assim como a responsabilidade social e ambiental, entre outros.

Ao analisarmos esses aspectos, notamos que as atribuições conferidas às Indicações Geográficas sob proteção da P.I. podem indicar características de qualidade, exclusividade e distintividade, como também aquelas historicamente atribuídas às marcas como sinais distintivos expressos por meio de conceitos que abrangem desde tendências estéticas até características técnicas desejadas pelo consumidor.

No que diz respeito aos desejos dos consumidores e à melhoria do produto, encontramos um nicho de mercado potencialmente promissor para a cachaça artesanal, o da cachaça artesanal orgânica, cuja matéria-prima, a cana-de-açúcar, é produzida sem o auxílio de insumos industrializados, em especial os agrotóxicos e fertilizantes químicos. 


\section{O mercado orgânico}

O mercado orgânico vem adquirindo cada vez mais importância em decorrência das diversas mudanças do meio ambiente e à contínua preocupação do homem com sua saúde. A agricultura orgânica, também conhecida como biodinâmica, biológica, natural ou agroecológica, pretende alcançar a sustentabilidade econômica e ecológica no encontro com a agricultura tradicional, a maximização dos benefícios sociais e a minimização da dependência de energia não renovável (JAKUBASZKO et al., 2005).

As possibilidades oferecidas pelos sistemas orgânicos, em se tratando de futuro da agropecuária, são amplas. Tais sistemas foram criticados anteriormente com a alegação de que se limitavam a uma produção de pequena escala e somente ao cultivo de frutas e hortaliças. Atualmente, percebe-se que não há limites, como também existe uma plataforma alternativa para uma diversidade de cultivos e criações. Esses avanços são observados no Brasil, onde existem cultivos e criações de pequena a grande escala certificados que atendem a um mercado crescente de mais de 50 produtos, principalmente comercializados in natura, ou, ainda, com beneficiamento primário, o que inclui soja, milho, citros, cana-de-açúcar, café, dendê, cacau, mandioca, algodão, tabaco, feijão, arroz, girassol, hortaliças, frutas tropicais e de clima temperado, carne bovina e leite, suínos, aves e ovos, mel e chá (JAKUBASZKO et al., 2005).

Segundo Wilkinson (2008), existe uma crescente evolução no mercado consumidor em torno de parâmetros sociais, ambientais e de saúde, o que leva a uma inclinação para os movimentos orgânicos de nível internacional os quais demandam normas certificáveis para produção orgânica. No Brasil, essas normas são idênticas e convergentes às do mercado internacional, visto que seguem as orientações da Federação Internacional do Movimento Orgânico (International Federation of Organic Movement IFOAM), como mostram os principais pontos do código de conduta dos produtores e outros atores que atuam ao longo da cadeia produtiva e que prevê penalidades no campo e na pós-colheita para as situações que não se alinhem com tais instruções (JAKUBASZKO et al., 2005):
1- Condições e requisitos para a conversão da unidade produtiva, que trazem um período de carência obrigatório.

2- Características da auditoria de certificação e condições para o uso do certificado de produto orgânico.

3- Condições sobre a identificação de embalagens e rótulos.

4- Condições de manejo dos aspectos gerais da propriedade, da cobertura florestal e do tratamento dos aspectos sociais (trabalhadores).

5- Requisitos sobre as fontes de adubos e o manejo das adubações.

6- Requisitos sobre insumos e manejo/controle de pragas e doenças, uso de reguladores de crescimento e condições de controle da contaminação.

7- Requisitos para a produção de mudas e sementes.

8- Requisitos para a criação animal e produção de produtos de origem animal.

9- Condições e requisitos para processamento, armazenamento, transporte e empacotamento de produtos orgânicos.

Essas normas certificáveis e com controle de aplicação estabelecem critérios mínimos para a conversão de sistemas convencionais em orgânicos, com base na não utilização de insumos industrializados e a recomendação de boas práticas de manejo e de fabricação.

O cenário da agropecuária orgânica no Brasil mostra-se peculiar, quando o maior dos desafios é o da busca pela certificação para a captura dos sobrepreços no mercado, o que contribui para a exclusão de muitos de agricultores que historicamente, cultivam sistemas naturais ou quase naturais e que permanecem à margem do mercado orgânico, em decorrência do custo que cerca a certificação (JAKUBASZKO et al., 2005).

Os desafios em termos de políticas públicas dispõem de uma estrutura capaz de endereçar às grandes demandas já citadas pelos atores sociais, mas atualmente os esforços desse poder se restringem apenas à regulamentação do setor. Segundo Costa (2007), os projetos de políticas públicas são 
capazes de subordinar interesses individuais aos interesses regionais e nacionais coletivos, buscados a médio e longo prazo através do planejamento do desenvolvimento e fundamentados em uma compreensão da estrutura sócio-econômica e na superação da situação de dependência e exploração, o que resulta significativamente na qualidade final dos produtos. Costa (2007) ainda afirma que cabe aos gestores públicos a disponibilização ampla e facilitada, casualmente subsidiada, de equipamentos de utilização coletiva para normatização, padronização, teste de qualidade de produtos e materiais, certificação e outros serviços de caráter tecnológico, além de técnicos capazes de orientar sobre o estabelecimento de padrões e normas, obtenção de certificações, registro de patentes e outros.

No que concerne ao raciocínio que permeia as políticas públicas, não é objetivo desta pesquisa adentrar nesse assunto, apenas mostrar sua existência e a que se refere.

Se a indução governamental de regulamentação da atividade agropecuária orgânica e da implantação de requisitos ambientais mostra-se como anseio de caráter geral, o consumidor e sua escolha individual estimulam decisões capazes de intervir na conduta dos agricultores. Desta forma, o mercado, cada vez mais atento em satisfazer às necessidades desse consumidor, cria uma infinidade de produtos dispostos a atender novos requisitos ambientais. É nesse cenário que se insere a cachaça, uma bebida genuinamente brasileira, reconhecida mundialmente, e que, a partir da agregação do valor de produção orgânica e artesanal, destaca-se pela qualidade diferenciada para um mercado potencialmente promissor.

De acordo com Silva et al. (2007), o mercado orgânico, sem aditivos químicos, cresce até 50\% ao ano, e, no setor da cachaça artesanal, diante de valores agregados, a bebida chega a custar o equivalente a quatro vezes mais o valor da cachaça industrial. Essa noção de valor agregado, observada como mecanismo tanto para aumentar quanto para reter rendas no âmbito da economia local, é atualmente focada em aspectos coletivos de proximidade e de território, com orientação para valorização de qualidades advindas da demanda do consumidor / cidadão (WILKINSON, 2008), o que explica o crescimento no setor.
Embora a produção artesanal e orgânica enfrente atualmente desafios com os concorrentes da cachaça industrial, esta se apresenta com um significativo potencial mercadológico a ser explorado considerando as tendências e o comprovado sucesso da bebida em termos globalizados.

\section{Comunicação mercadológica}

Pensar em um potencial mercadológico a ser explorado nos conduz às competências comunicacionais. Trata-se da utilização da comunicação como ferramenta de marketing, que por meio de suas articulações consegue adentrar em culturas, hábitos, tradições, valores e crenças, transformando um produto cotidiano, constituído de diversos significados, em algo repleto de valores agregados, elitizado, desejado para o consumo. Enfim, a comunicação possibilita mudanças significativas, em que novos rótulos, novas práticas e novas posturas passam a permear o mercado competitivo entre as concorrências de produção. Deste modo, os processos comunicativos acabam representando formas de estimular e viabilizar as trocas, personalizar os discursos e outras tantas possibilidades que, para Galindo (2008), fazem surgir um novo cenário que tem produzido um efeito amplo e profundo na criação de sentidos e na carga simbólica atribuída tanto às marcas como à imagem corporativa.

Ao refletirmos sobre a questão de que o marketing possui uma relação estreita entre produção, capacidade produtiva, disponibilidade de determinada produção que condiz à garantia do seu destino ao consumidor final e a possibilidade da mudança do sua escolha, pode-se dizer que a presença do consumidor em si não garante a aquisição do produto ou mesmo a reincidência do consumo. Galindo (2008, p. 33) afirma que "o fato de os consumidores não dependerem de nenhum produto de uma empresa é em parte responsável pela existência do marketing e de sua complexa estrutura." Eis que surge a abordagem organizacional de satisfação de desejos e necessidades dos consumidores a fim de atingir objetivos lucrativos, na qual o papel da comunicação ganha maior expressividade ao mesmo tempo em que se confunde com a atividade do marketing, visto que se constitui uma estratégia visível que antecede a comunicação do próprio produto, com seus atributos e propostas diferenciadas frente à concorrência. 
Ainda neste raciocínio, Galindo (2008, p.36) pontua que a comunicação mercadológica pretende produzir a venda imediata; aumentar a frequência de compra do produto; informar sobre seus usos; aumentar o número ou qualidade dos intermediários; aumentar a participação de mercado; contribuir para a imagem da empresa; construir imagem, preferência ou aceitação da marca; criar uma reputação para a marca; atingir segmentos populacionais; desenvolver mercados externos; criar e manter contato com diversos públicos-alvo; construir demanda; informar sobre o produto e sua disponibilidade do produto; modificar apelos de compra e suas motivações; auxiliar vendedores.

Neste sentido, a comunicação mercadológica busca resultados eficazes em sua pretensão do alcance dos seus objetivos e, para tanto, se baseia no produto e suas características, no monitoramento da concorrência e dos hábitos e crenças, mitos e ritos dos consumidores potenciais.

No quesito de hábitos e crenças, elucidamos a cultura que é utilizada como ferramenta de comunicação na construção da identidade. Lucena (2000, p.4) pontua que:

a cultura, à luz das ciências sociais, refere-se ao modo de vida de um povo, em toda sua extensão e complexidade. Também pode ser entendida como manifestação espontânea de um determinado grupo social. Esta, uma vez incorporada ao seu cotidiano, o caracteriza e o distingue dos demais.

Assim como a cachaça que se constitui como um elemento da cultura popular e um dos referenciais da identidade cultural de Minas Gerais e tantas outras regiões do país.

A comunicação em seu processo se vale do folkmarketing, como uma vertente da comunicação e seu discurso folclórico, para expressar os interesses regionais por meio das manifestações e elementos da cultura com o intuito de promover e estimular a identificação (LUCENA, 2000), o que explica todos os porquês das mudanças de status sofridas pelo produto cachaça e também do comportamento por parte do consumidor.

Em síntese, a comunicação e seus recortes explicam determinada realidade, nas condições de produção e recepção entre os interlocutores, enfatizando seu papel social interativo que ocorre em um contexto de intencionalidade.

\section{Considerações Finais}

O mercado da cachaça artesanal orgânica se encontra em constante ascensão, diante de sua representação e seus significados simbólicos, os quais se inserem no contexto social, cujas questões condizentes à moralidade não se sobressaem à elitização e ao consequente consumo do produto. Deste modo, com o passar dos tempos, houve uma mudança drástica que se atribui ao processo de comunicação como ferramenta de marketing tanto no perfil do consumidor da cachaça e na valorização do produto que acompanha uma tendência mercadológica que advém da sustentabilidade e do observado como "moda", quanto na atuação do agricultor familiar, ou seja, o pequeno produtor da bebida que sofre todas as interferências dessa demanda e se vê em uma situação de marginalidade diante das exigências legais e da necessidade de adequação trabalhista, o que torna necessário o desenvolvimento de políticas públicas que contemplem essa realidade.

\section{Referências}

BARBOSA, L. Tendências da alimentação contemporânea. In: PINTO, M.L., PACHECO, J.K. (Orgs.) Juventude, consumo \& educação 2. Porto Alegre: ESPM, 2009.

BARBOSA, P.M.S. A importância do uso de sinais distintivos coletivos: Estudo de caso da Indicação de Procedência "Paraty"do estado do Rio de Janeiro - Brasil. 2011. 196f. Dissertação (Mestrado Profissional em Propriedade Intelectual, Inovação e Desenvolvimento) Instituto Nacional de Propriedade Industrial - INPI, Rio de Janeiro, RJ.

CARNEIRO, M.J. Em que consiste o familiar da agricultura familiar? In: COSTA, L.F.C., FLEXOR, G., SANTOS, R. (Orgs.) Mundo rural brasileiro: ensaios interdisciplinares. Rio de Janeiro: Mauad X; Seropédica, RJ: EDUR, 2008.

. Multifuncionaliddae da agricultura e ruralidade: uma

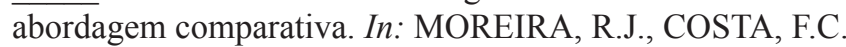
(Orgs.). Mundo rural e cultura. Rio de Janeiro: Mauad, 2002.

Agricultores familiares e pluriatividade: tipologias e políticas. In: COSTA, L.F.C., BRUNO, R., MOREIRA, R.J. (Orgs.). Mundo rural e tempo presente. Rio de Janeiro: Mauad, 1999.

COSTA, E. J. M. Políticas públicas e o desenvolvimento de arranjos produtivos locais em regiões periféricas. 2007. 409f. Tese (Doutorado em Economia Aplicada) - Instituto de Economia, Universidade Estadual de Campinas, Campinas, São Paulo. 
GALINDO, D. (Org.). Comunicação mercadológica: uma visão multidisciplinar. São Bernardo do Campo: Universidade Metodista de São Paulo, 2008.

GONÇALVES, P. R. A fumaça da discórdia: da regulação do consumo e o consumo do cigarro. 2006. $127 \mathrm{f}$. Dissertação (Mestrado em Antropologia) - Universidade Federal Fluminense, Niterói, Rio de Janeiro.

SEBRAE. Cachaça Artesanal: estudos de mercados. Série Mercado. ESPM, 152p. 2008.

SILVA, L. S.; CINTRA, K. N. M.; KIIL, L. C., et al. A cachaça orgânica e artesanal e suas perspectivas nos mercados nacional e internacional. In: I ENCONTRO CIENTÍFICO E I SIMPÓSIO DE EDUCAÇÃO UNISALESIANO, 2007, Lins-SP. Anais... Disponível em: <http://www.unisalesiano. edu.br/encontro2007/trabalhosaceitos.html> Acesso em 19 de abril de 2011.

JAKUBASZKO, R.; LUCHIARI Jr. A.; GAZZONI, D.L. et al. Marketing da terra. Viçosa: UFV, 2005

LUCENA, S. Cachaça e rapadura, símbolos da comunicação popular em Areia: Paraíba - Brasil. Santiago do Chile: V Congresso Latino Americano de Ciências de la Comunicação - ALAIC, 2000.

WILKINSON, J. A agricultura familiar ante o novo padrão de competitividade do sistema agroalimentar no Brasil e na América latina. In: COSTA, L.F.C., FLEXOR, G., SANTOS, R. (Orgs.). Mundo rural brasileiro: ensaios interdisciplinares. Rio de Janeiro: Mauad X; Seropédica, RJ: EDUR, 2008.

VERDI, Adriana Renata. Dinâmicas e perspectivas do mercado de cachaça. Informações Econômicas, São Paulo, v.36, n.2, p.93-8, fev. 2006. Disponível em: <http://www. apta.sp.gov.br/cachaca/upload/publica/not13.pdf $>$. Acesso em: 01 Abril. 2011.

\section{Sites pesquisados}

ABRABE - http://www.abrabe.org.br

INPI - http://www.inpi.gov.br

Recebido em: 7 de agosto de 2012

Aceito em: 17 de setembro de 2012 